Research Article

\title{
Multiphase Flow Coupling Behavior of Bubbles Based on Computational Fluid Dynamics during AFP Process: The Behavior Characteristics of Bubbles during AFP Process
}

\author{
Jinglan Guo $\mathbb{1}^{1}$ and Siyuan Wang ${ }^{2}$ \\ ${ }^{1}$ School of Mechanical and Power Engineering, Harbin University of Science and Technology, No. 52, Xuefu Street, \\ Harbin 150080, China \\ ${ }^{2}$ School of Mechatronics Engineering, Harbin Institute of Technology, No. 92, Xidazhi Street, Harbin 150001, China \\ Correspondence should be addressed to Jinglan Guo; guojinglan@hrbust.edu.cn
}

Received 13 April 2021; Accepted 27 July 2021; Published 31 July 2021

Academic Editor: Aniello Riccio

Copyright (C) 2021 Jinglan Guo and Siyuan Wang. This is an open access article distributed under the Creative Commons Attribution License, which permits unrestricted use, distribution, and reproduction in any medium, provided the original work is properly cited.

\begin{abstract}
To investigate the mechanism of the effect of process parameters on bubble flow behavior during automated fiber placement (AFP) and the relationship between the bubble and voids, mechanical properties of laminates, this paper analyzes the multiphase flow coupling behavior of the bubble and fiber formation using computational fluid dynamics (CFD) and finite element (FE) method under different AFP process parameters. The effects of AFP process parameters on bubble characteristics and fiber deformation are then discussed, respectively, including bubble displacement, maximum cross-sectional area, the lowest internal temperature of the bubble, bubble breakup, and maximum deformation of the fiber. Furthermore, the AFP and corresponding test experiments are performed to investigate the relationships between different bubble characteristics and void content, mechanical properties, mainly interlaminar shear strength (ILSS) and flexural strength (FS). The results show that the maximum cross-sectional area of bubbles is closely related to the AFP process parameters. The FS and ILSS are positively correlated with the maximum crosssectional area. With the increase of bubble displacement and fiber maximum deformation, FS and ILSS are first increased and then decreased.
\end{abstract}

\section{Introduction}

Fiber Reinforced Plastics/composites (FRPs) have been widely used for many years in the aerospace, naval, automotive, and civil applications due to their several advantages over traditional materials (e.g., metals), such as high stiffness and strength to weight ratio, more excellent fatigue resistance, better long-term durability, lower thermal expansion and superior corrosion resistance [1-4]. Such advantages make FRPs an ideal candidate for a wide range of applications involving extreme operational conditions [5-8]. The manufacturing method of FRP includes hand layup, molding, pultrusion, filament winding, automated tape laying, and automated fiber placement. Among them, automated fiber placement (AFP) appeared in the 1970s in the aerospace industry. It combines the advantages of filament winding and automated tape laying to overcome their limitations and exploit their benefits, which is one of the fastest-growing and most effective fully automated manufacturing technologies for composite materials in recent years [9-12]. An AFP machine usually consists of a placement head and another functional mechanical structure (a robotic arm or gantry structure). The placement head lays prepreg tows onto a mold to construct the layup. Depending on the shape of the mold surface, the AFP process can use multiple prepreg tows (8 32 tows), or realize continuous variable angle placement. Additionally, it can cut/refeed the tow to adapt to the change of the manufacturing boundary, which can guarantee the processing requirements of complex structures [13-15]; see Figure 1. 


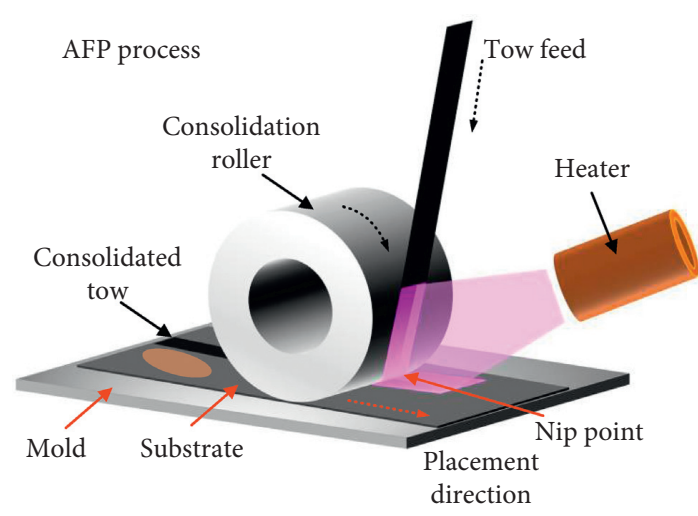

FIgURE 1: Automated fiber placement (AFP) process.

Due to the complexity of the AFP manufacturing process, such as multiple process parameters, prepreg defects, and manufacturing errors, the laminates are not exempt from imperfections that include gaps and/or overlaps, twisted tows, fiber waviness, and voids. They often appear in the final component, thereby affecting the mechanical performance. Among them, voids can significantly affect the mechanical properties of composites [16-18], which result from the small bubbles in the prepreg itself, the volatilization of the resin caused by the preheating process, low laying pressure, small air pockets, and so forth. Air bubbles in the process of AFP are an essential cause of voids formation, which are closely related to the AFP process parameters.

With regard to the characteristics of voids during the AFP process, Ranganathan et al. $[19,20]$ proposed a novel model to establish an in situ AFP process of thermoplastic composites using a Newtonian fluid in a two-dimensional geometry, which can predict the final void content and the thickness of a composite part as a function of the laying speed and compaction pressure under nonisothermal conditions. Similarly, Tierney and Gillespie [21] developed some integrated models, such as the heat transfer model, void dynamics model, and multiscale void transport model, for predicting the heat transfer and void dynamics within the laminate. The results indicate that obvious gradients in final void content exist through the thickness and are closely related to processing parameters including the heating temperature, laying speed, and heater height. Simacek et al. [22] established a dynamic model of the voids of thermoplastic composites manufactured by the AFP technique. The model combines the internal pressure of the bubble, the response of the fiber matrix, the pressure of the compaction roller, and the pressure of resin to analyze the process of the resin diffusing from the resin-rich region to fill the bubble. Khan et al. [23] developed a simulation tool from the existing available model in literature [19-21]. The effects of compaction force, laying speed, and hot gas flow in the heating region on the void development were investigated through simulation. Then, experiments were performed to manufacture composite laminates. Void distributions from simulations were compared with the experiments. The results show that the simulation method is feasible. SeanzCastillo et al. [24] investigated the effect of process parameters on voids and the mechanical performance of $\mathrm{CF} /$ PEEK composites. Three different out-of-autoclave technologies were used, including vacuum bag, hot-press, and thermoplastic automated fiber placement (TP-AFP) with in situ consolidation (ISC). The void content was obtained using density method, 2D microscopy, matrix acid digestion, and C-scan, respectively, thus summarizing the benefits and scope of various methods. The results find that ISC voids appear mainly in the upper laminates because the bottom layers can suffer more rolling times by compaction roller. This paper only considers the effect of temperature during the TP-AFP process while other process parameters are not considered.

In summary, a few kinds of literature have examined the voids of thermoset materials during the AFP process. However, the bubbles in the thermoset laminates during the AFP process were rarely studied. Due to the curing process, the bubbles during the AFP process are not final defects. But the literature of [25] indicated that a specific relationship exists between the bubbles before curing and the voids in the laminate after curing. Also, the mechanism of the effect of AFP process parameters on bubble flow behavior is not yet clear. So it is difficult to understand the mechanism of controlling defects in process optimization. To aid in such an understanding, this paper investigates the relationship between the bubble behaviors and the AFP process parameters, void content, and mechanical properties using computational fluid dynamics (CFD) and finite element (FE) method. The rest of this paper is organized as follows: in Section 2, the multiphase flow mesomodel is established using the CFD and FE method, including the control equations of CFD, fluid-solid coupling model, fluid-gas coupling model, and their analysis conditions. According to analysis results, the effect of AFP process parameters on bubble characteristics and fiber deformation are then discussed in Section 3. Lastly, the AFP and testing experiments are performed to reveal the relationship between void content, mechanical properties, and bubble characteristics.

\section{Materials and Methods Layout Mesomodel and Analysis Conditions}

2.1. Control Equations. The molten resin is an incompressible fluid with a certain viscosity. The Navier-Stokes equations (N-S Equations) describe the motion characteristics of a viscous incompressible fluid based on momentum conservation. When the differential equation of motion, constitutive equation, state equation, and continuity equation are closed, the density is assumed to be constant, so the continuity equation is set as 0 , as described in

$$
\operatorname{div}(v)=0,
$$

where div represents divergence.

At this time, the simplified equation with three velocity components as variables is N-S Equations. It assumes that the density is constant, so it is suitable for incompressible fluids which conform to the generalized Newtonian viscosity assumption. Because the resin in prepreg could melt and 
flow under the action of AFP process parameters, the flow state of resin is incompressible. Thus, N-S Equations can reflect the basic motion law of actual fluids and are suitable for studying the flow characteristics of resins during the AFP process:

$$
\left\{\begin{array}{l}
\rho \frac{d u}{d t}=-\frac{\partial p}{\partial x}+\rho X+\mu \nabla u, \\
\rho \frac{d v}{d t}=-\frac{\partial p}{\partial y}+\rho Y+\mu \nabla v, \\
\rho \frac{d w}{d t}=-\frac{\partial p}{\partial z}+\rho Z+\mu \nabla w,
\end{array}\right.
$$

where $\rho$ is the density of the fluid; $u, v, w$ are the velocity components of the fluid at time $t ; X, Y, Z$ are the components of external force; $p$ is the pressure; $\mu$ is the dynamic viscosity; and $\nabla$ is the Laplace operator.

The Reynolds stress model (RSM) based on N-S Equation is directly embedded in ANSYS-CFD, which can obtain an accurate viscous model and turbulent state. Reynolds number is an important parameter in RSM. The calculation method is as follows:

$$
\operatorname{Re}=\frac{\rho v D}{\mu},
$$

where $v, \rho$, and $\mu$ are the velocity, density, and viscosity coefficient of the fluid, respectively, and $D$ is a characteristic length.

Reynolds number can be used to distinguish whether the fluid flow is laminar flow or turbulent flow and can also be used to determine the resistance of the object in the fluid flow. We can obtain the Reynolds number of resin under different process parameters by Figure 2 and Table 1. Other boundary conditions are shown in Table 2 .

\subsection{Multiphase Flow Mesomodel}

2.2.1. Fluid-Solid Coupling Model. This subsection uses the computational fluid dynamics (CFD), combining ANSYSCFD and statics modules to construct the mesomodel of prepreg during the AFP process for investigating the behavior of bubbles in preforms and deformation of fibers under different process parameters. This model consists of three phases with fluid-solid-gas, including resin, fibers, and bubble in the resin. The thickness of the model is set as $0.2 \mathrm{~mm}$. The contact length between the rigid roller and the resin is considered as about $0.4 \mathrm{~mm}$, which is in accordance with the prepregs for subsequent experiments. The carbon fibers are wrapped in resin, wherein the diameter of the carbon fiber is set to $0.03 \mathrm{~mm}$. The established fluid-solid two-phase model is shown in Figure 2.

2.2.2. Fluid-Gas Coupling Model. The fluid part is automatically meshed using the CFD mesh type. When studying the behavior of bubbles in resin, it contains two phases of resin and air, in which these two phases first need to be

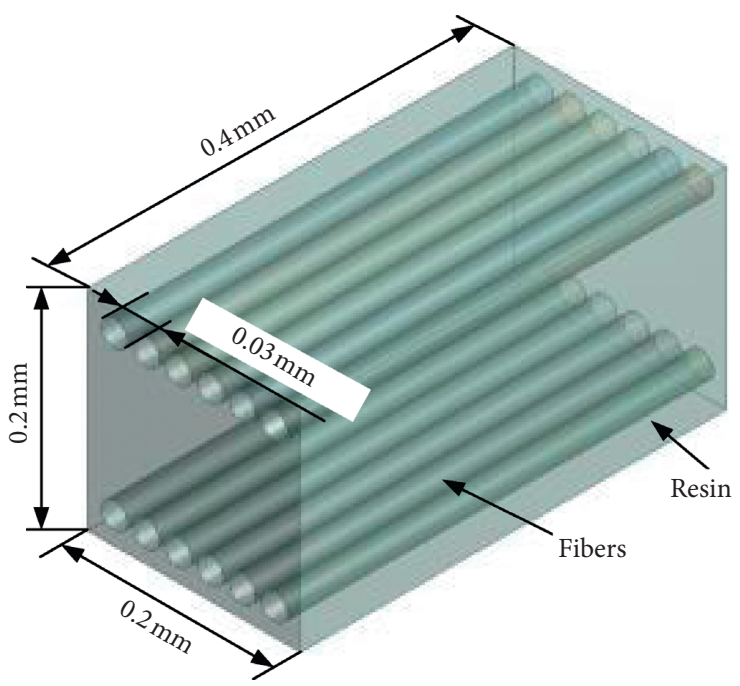

FIgURE 2: Fluid-solid coupling geometric model.

calculated separately. Therefore, the Volume of Fluid (VOF) model in the multiphase flow model is selected, defining the number of phases as 2. Using this model, the phase interface between resin and air can be simulated to evaluate the movement and deformation of bubbles in resin under different process conditions. Related material properties are shown in Table 1.

In order to simplify the model, consider that the preheating temperature has a great influence on the viscosity. Moreover, the resin has a small change in density, specific heat, and thermal conductivity at a low-temperature gradient (changes within $10^{\circ} \mathrm{C}$ ). Thus, the model only considers changes in resin viscosity with temperature. The air viscosity does not change much with temperature so that it can be ignored in the simulation. Through the experimental test of the prepreg manufacturers, the viscosity of the resin at $30^{\circ} \mathrm{C}$ $(303 \mathrm{~K}), \quad 40^{\circ} \mathrm{C} \quad(313 \mathrm{~K})$, and $50^{\circ} \mathrm{C}(323 \mathrm{~K})$ is about $10000 \mathrm{MPa} \cdot \mathrm{s}, 3000 \mathrm{MPa} \cdot \mathrm{s}$, and $1000 \mathrm{MPa} \cdot \mathrm{s}$, respectively.

Since the movement speed of the fluid is determined by both the laying pressure (compaction force) and the laying speed, in order to simplify the model, assuming that the pressure is in a static and constant state, then the movement speed of the fluid is completely determined by the laying speed. In this way, we set the linear speed of the pressure roller (laying speed) as the inlet speed of the fluid in contact with the pressure roller. The laying pressure can be set to constant inlet pressure. The outlet velocity is related to the inlet pressure and laying speed and is a variable. The singlefactor simulation parameters are shown in Table 2.

In order to distinguish between resin and bubbles in the prepreg, it is necessary to provide the air phase region of the fluid region, where a spherical shape with a spherical center coordinate of $(0.1 \mathrm{~mm}, 0.1 \mathrm{~mm}, 0.075 \mathrm{~mm})$ and a radius of $0.05 \mathrm{~mm}$ is divided. Then, the phase region is set to air property. Thus, a fluid-gas coupling initial model is established, as shown in Figure 3(a), which shows the initial state and position of the bubble (the middle section of the $3 \mathrm{D}$ model). The air temperature is set at room temperature to investigate the effect of the process parameters on the 
TABLE 1: Material properties in fluid analysis.

\begin{tabular}{lcccc}
\hline Phase & Density $\rho\left(\mathrm{g} \cdot \mathrm{cm}^{-3}\right)$ & Specific heat capacity $c\left(\mathrm{~J} \cdot \mathrm{kg}^{-1} \cdot \mathrm{K}^{-1}\right)$ & Thermal conductivity $\lambda\left(\mathrm{W} \cdot \mathrm{m}^{-1} \cdot \mathrm{K}^{-1}\right)$ & Viscosity $\mu(\mathrm{MPa} \cdot \mathrm{s})$ \\
\hline Resin & 1.2 & 1511 & 0.2 & $1000 / 3000 / 10000$ \\
Air & $1.225 \times 10^{-3}$ & 1006.43 & 0.0242 & $1.7894 \times 10^{-2}$ \\
\hline
\end{tabular}

TABLE 2: The single-factor simulation parameters.

\begin{tabular}{lcccc}
\hline No. & Laying pressure $P(\mathrm{MPa})$ & Laying speed $v(\mathrm{~mm} / \mathrm{s})$ & Preheating temperature $T(\mathrm{~K})$ & Resin viscosity $\mu(\mathrm{Pa} \cdot \mathrm{s})$ \\
\hline 1 & 0.5 & 40 & 323 & 1000 \\
2 & 0.5 & 40 & 313 & 3000 \\
3 & 0.5 & 40 & 303 & 10000 \\
4 & 1.1 & 40 & 303 & 10000 \\
5 & 1.7 & 40 & 303 & 10000 \\
6 & 0.5 & 30 & 303 & 10000 \\
7 & 0.5 & 20 & 303 & 10000 \\
\hline
\end{tabular}

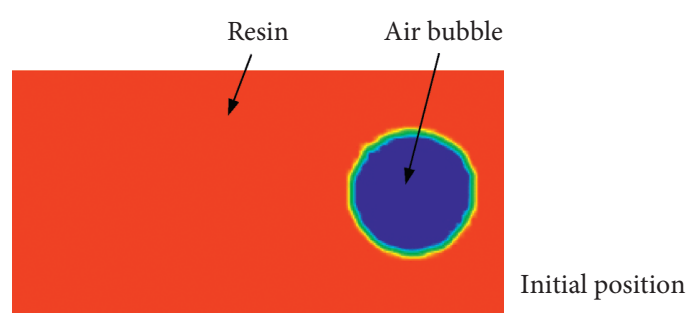

(a)

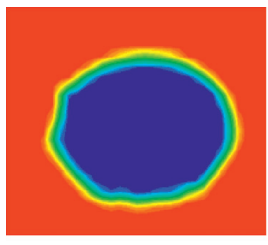

2500 steps

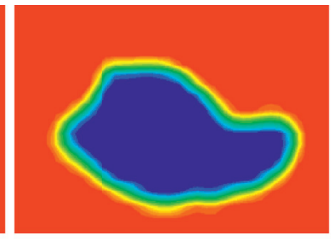

5000 steps

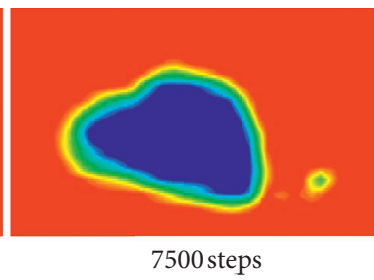

7500 steps

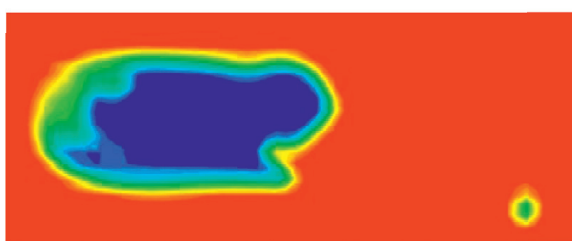

Final position

(b)

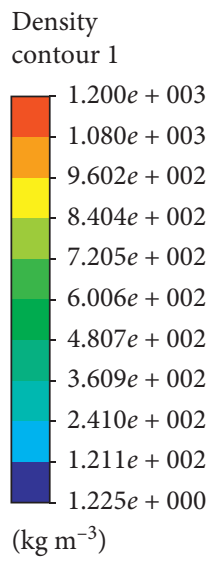

$\left(\mathrm{kg} \mathrm{m}^{-3}\right)$

FigURE 3: Fluid-gas coupling model and simulations. (a) Fluid-gas coupling initial model. (b) The evolution behaviors of the bubble in the fluid at the laying pressure of $0.5 \mathrm{MPa}$, the laying speed of $40 \mathrm{~mm} / \mathrm{s}$, and the preheating temperature of $323 \mathrm{~K}$.

internal temperature of the bubble. According to the simulation boundary conditions, the evolution behaviors of the bubble in the fluid are further simulated under different AFP process parameters. See Figure 3(b).

\section{Effect of AFP Process Parameters on Bubble Characteristics and Fiber Deformation}

3.1. Results. The deformation simulations of the carbon fiber are performed based on the fluid-solid coupling model after fluid-gas simulations. The carbon fiber density is set to $1.78 \mathrm{~g} / \mathrm{cm}^{3}$, Young's modulus is $125 \mathrm{GPa}$, and Poisson's ratio is 0.34 . The principle is that the results calculated by the fluid-gas simulations are applied to the carbon fiber through the fluid-solid coupling interface. The effects of different process parameters on bubble motion characteristics and fiber deformation are explored below. The main characteristics examined include the displacement of the bubble motion $\left(D_{\mathrm{bm}}\right)$, the maximum cross-sectional area of the bubble $\left(A_{\max }\right)$, the internal lowest temperature of the bubble $\left(T_{\text {int }}\right)$, and the maximum deformation of the fiber $\left(D_{\text {fmax }}\right)$. Due to the large difference between the color of the bubbles and the resin, the size of the bubble is obtained by the grayscale recognition method using Image-pro Plus to obtain the change of the cross-sectional area of the bubble during the movement. The behavior characteristics of bubbles and the 
gray-scale recognition method under different process parameters are shown in Figure 4. Bubble internal temperatures under different preheating temperatures are shown in Figure 5. Fiber deformations under different process parameters are shown in Figure 6. Figures 3-5 are based on the fluid-gas coupling model. Figure 6 is obtained by the fluidsolid coupling model.

3.2. Discussions. The relationship between different process parameters and characteristic parameters is obtained through multiphase flow simulations, which can be listed in Table 3.

From Table 3, the bubble motion displacement in the resin is mainly related to the laying pressure and preheating temperature. The displacement increases with the increase of the laying pressure and preheating temperature. However, the laying speed has little effect on the displacement compared with other process parameters. Air bubbles are compressible fluids, so when the boundary conditions change, the bubble cross-sectional area will change. The results show that the higher the laying pressure has, the smaller the cross-sectional area of the bubble is. Interestingly, the laying speed is opposite to that, which has a positive correlation with the cross-sectional area of the bubble. Additionally, bubbles are easy to break up at higher laying speed and preheating temperature or longer displacement (more than $200 \mu \mathrm{m}$ ). But the bubbles seem to be breaking up at the laying speed of $20 \mathrm{~mm} / \mathrm{s}$ and $30 \mathrm{~mm} / \mathrm{s}$. It is inferred that the slower speed may also result in the bubbles breaking up. Different laying pressures can also affect the internal temperature of the bubble except for the preheating temperature. It may be due to the reduced cross-sectional area of the bubbles and the faster heat conduction. For fiber deformation, except that the laying pressure has a significant effect on the maximum deformation of the fiber, other process parameters have no obvious effect on this parameter.

\section{The Relationship between Bubble Behaviors and Void Defects}

4.1. Experiments. According to 7 groups of processing parameters, the laying experiments are carried out using an AFP machine. Considering the subsequent testing of void content and corresponding mechanical properties, it is necessary to perform curing experiments on 7 groups of AFP samples. During curing, the resin in the sample can undergo a cross-linking chemical reaction with the latent curing agent. Here, if air bubbles cannot be discharged from the resin, they will remain inside the sample to form void defects. It can be seen that the bubble content before curing can affect the void content. However, the degree of chemical reaction of the resin is related to the curing pressure and curing temperature, which can change the difference of the voids caused by the AFP process. Thus, 7 groups of samples are cured by an identical curing process using a vacuum bag and an autoclave to remove any variation at the voids due to the curing. The curing process parameters are the vacuum degree of $2 \mathrm{~Pa}$, curing pressure of $0.5 \mathrm{MPa}$, curing temperature of $120^{\circ} \mathrm{C}$, and curing time of $120 \mathrm{~min}$. Afterwards, the void content is identified by the photomicrography method. Universal Testing Machine further tests interlaminar shear strength (ILSS) and flexural strength (FS) of the samples. The experimental setup is shown in Figure 7.

4.2. Bubbles and Voids. In order to improve the accuracy of the void content, we select three test specimens and their 6 fields of view for each sample. Thus, each sample uses 18 fields of view to test the voids. So, their average value can be considered as the void content of a sample. According to the obtained void content under different AFP process parameters, the relationship between voids and bubble characteristic parameters is shown in Figure 8.

The trends of void variation are fitted by a B-spline curve. From Figure 8, the void content decreases first and then increases as the bubble displacement increases, in which the critical value is about $70 \mu \mathrm{m}\left(D_{\mathrm{bm}}\right)$. It is found that too long or too short bubble displacement is beneficial to increase the void content. When the bubble is extremely moving, it has two functions. First, the bubbles have the phenomenon of expulsion [26], which accelerates the removal of the bubbles from the fluid. The second is that the bubbles will converge, leading to the convergence of microbubbles, which is conducive to the detection of microphotography. From this point, the expulsion effect is significant before the displacement is $70 \mu \mathrm{m}$. The longer the displacement is, the more obvious the expulsion is. Also, the convergence effect can increase significantly after $70 \mu \mathrm{m}$. Bubble convergence intensifies as displacement increases within this range. Similarly, the relationship between the maximum deformation of fibers and void content shows similar trends as that of the bubble displacement. It can be inferred that fiber deformation may also have a certain effect on the expulsion and convergence of bubbles. Interestingly, bubble cross-sectional area and void content present a negative correlation. This may be due to the fact that the larger cross-sectional area is helpful to bubble convergence and expulsion. But there is an inflection point at $0.85 \mathrm{~mm}^{2}$, which reflects that the crosssectional area between $0.78 \mathrm{~mm}^{2}$ and $0.85 \mathrm{~mm}^{2}$ has little effect on the void content. Subsequently, the void content decreases rapidly with the increase of cross-sectional area, which is due to the poor motion ability of bubbles with a cross-sectional area of $0.78-0.85 \mathrm{~mm}^{2}$, which is not conducive to bubble convergence and expulsion. Also, the decrease of the laying speed could determine the above relationship. Additionally, there is no obvious correlation between void content and bubble internal temperature. It can be seen that temperature has a lower effect on the void content.

4.3. Bubbles and Mechanical Properties. This subsection investigates the relationship between bubble characteristic parameters and mechanical properties, including interlaminar shear strength (ILSS) and flexural strength (FS). Each sample selects three specimens for testing. The results are shown in Figure 9. 


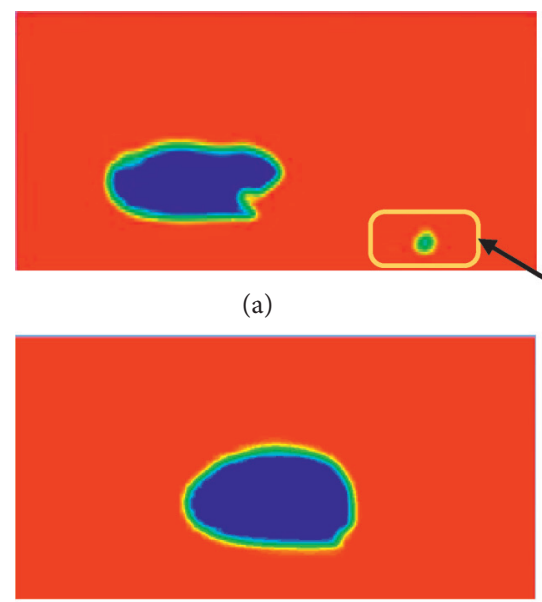

(d)

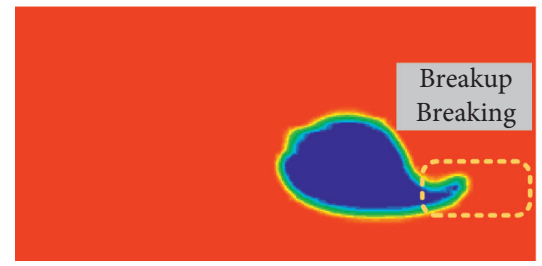

(g)

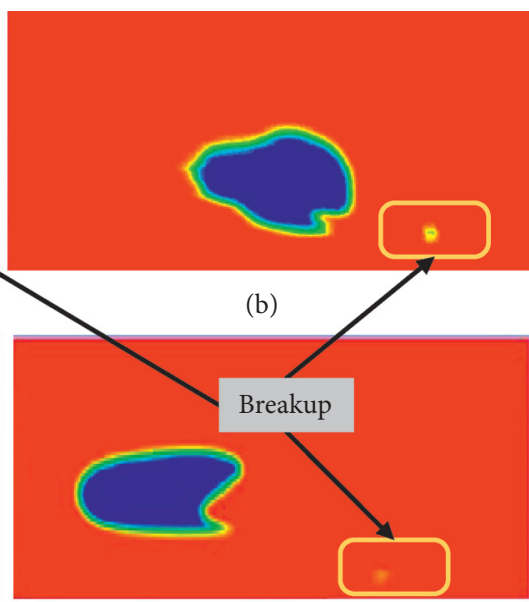

(e)

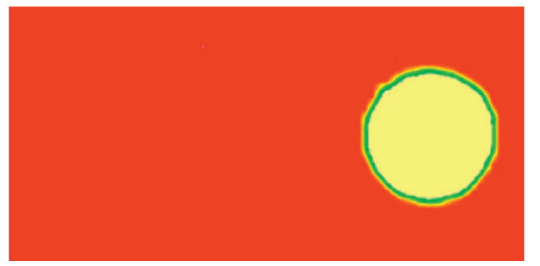

(h)

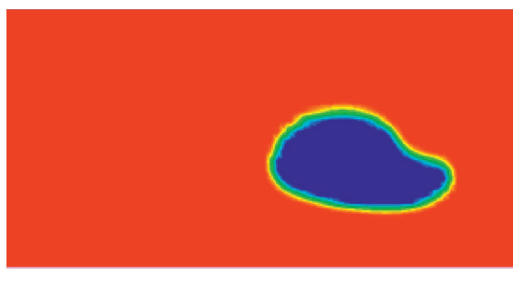

(c)

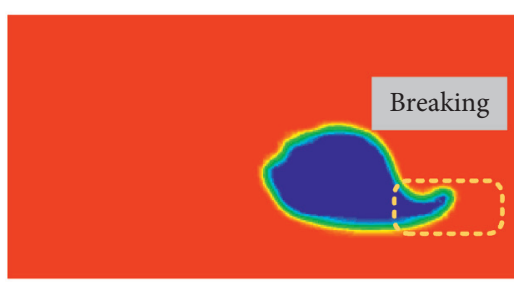

(f)

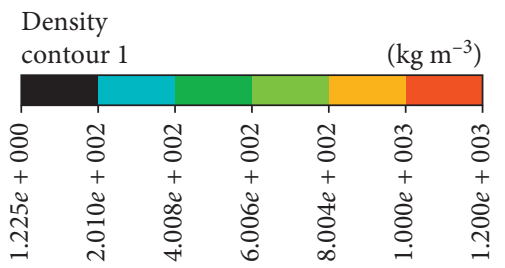

Figure 4: The behavior characteristics of bubbles and the gray recognition method under different process parameters. (a) (g) The behavior characteristics of bubbles under different AFP process parameters, where the numbers are consistent with Table 2. (a) No. 1. (b) No. 2. (c) No. 3. (d) No. 4. (e) No. 5. (f) No. 6. (g) No. 7. (h) Gray-scale recognition process.

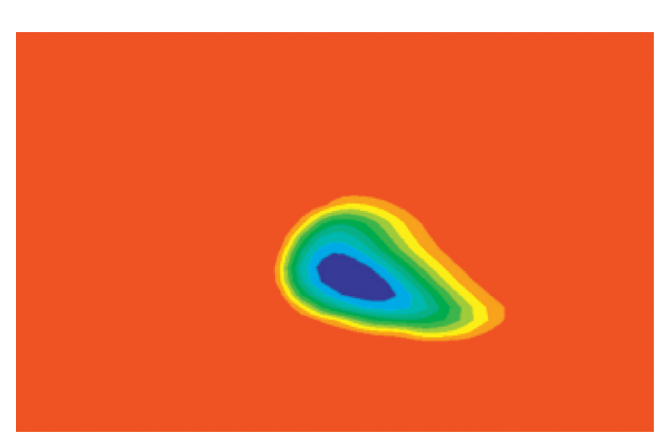

(a)

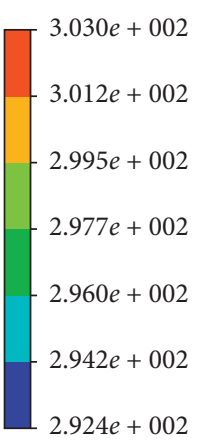

(K)

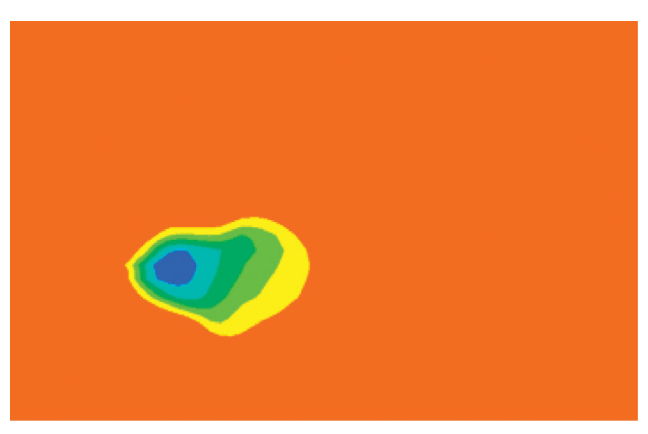

(b)

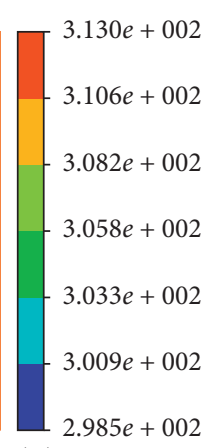

$(\mathrm{K})$

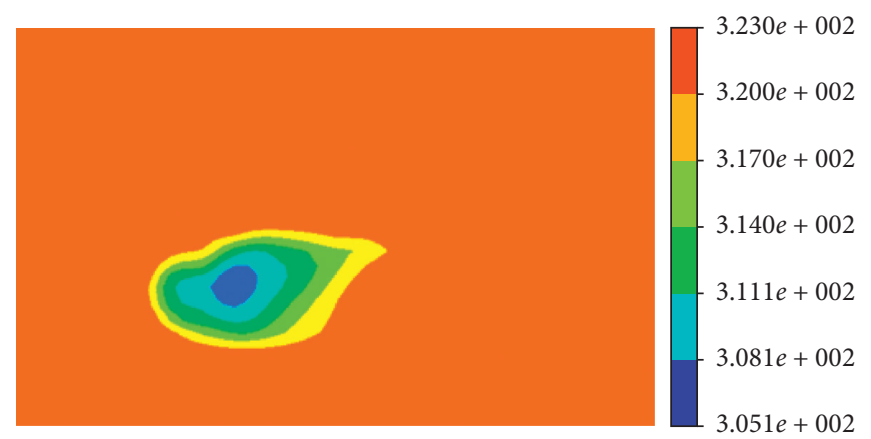

(K)

(c)

FiguRE 5: Bubble internal temperatures under different preheating temperatures at the laying pressure of $0.5 \mathrm{MPa}$ and the laying speed of $40 \mathrm{~mm} / \mathrm{s}$. (a) The preheating temperature of $303 \mathrm{~K}$. (b) The preheating temperature of $313 \mathrm{~K}$. (c) The preheating temperature of $323 \mathrm{~K}$. 


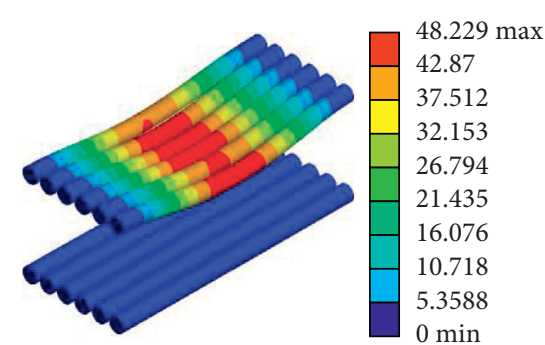

(a)

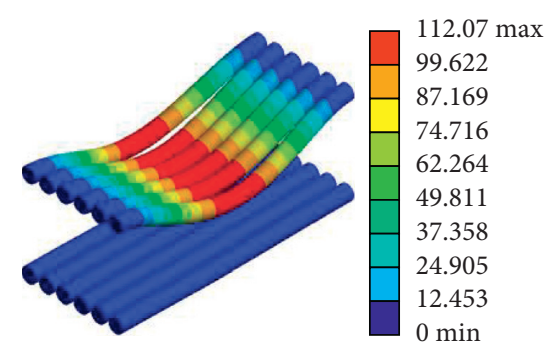

(d)

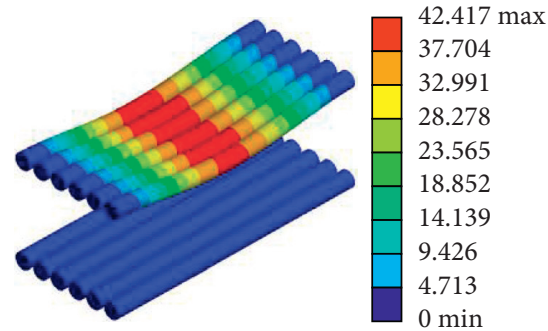

(b)

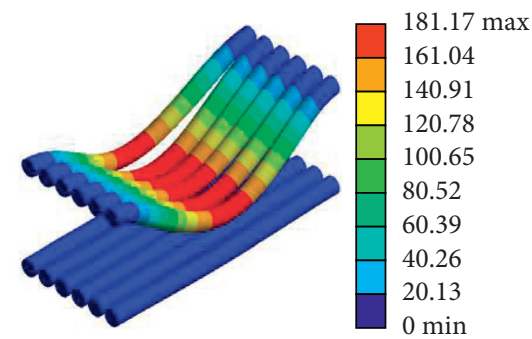

(e)

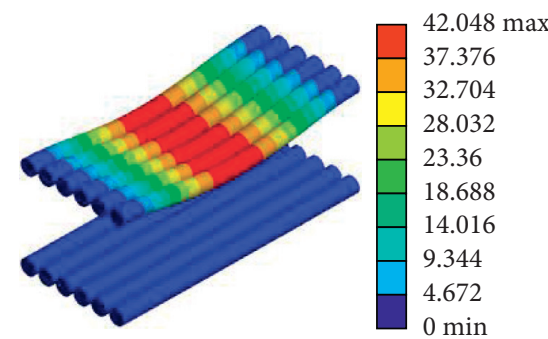

(g)

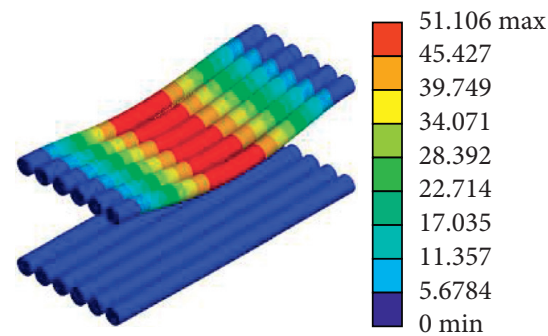

(c)

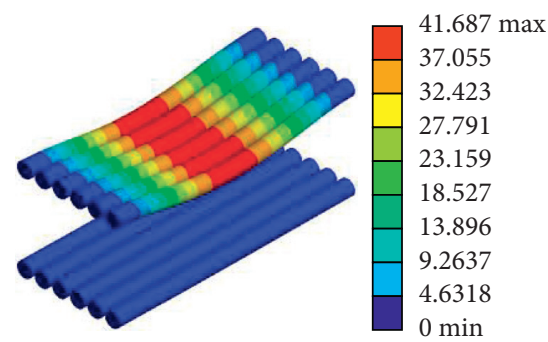

(f)

Figure 6: Fiber deformations under different process parameters. (a) (g) The numbers are consistent with Table 2. (a) No. 1. (b) No. 2. (c) No. 3. (d) No. 4. (e) No. 5. (f) No. 6. (g) No. 7.

TABLE 3: Characteristic parameters under different AFP process parameters.

\begin{tabular}{lcccccc}
\hline No. & AFP process parameters $(\mathrm{MPa}-\mathrm{mm} / \mathrm{s}-\mathrm{K})$ & $D_{\mathrm{bm}}(\mu \mathrm{m})$ & $A_{\max }(\mathrm{mm} 2)$ & Breakup & Tint $(\mathrm{K})$ & $D_{\mathrm{fmax}}(\mu \mathrm{m})$ \\
\hline 1 & $0.5-40-323$ & 200 & 0.0851 & + & 305 & 48.229 \\
2 & $0.5-40-313$ & 130 & 0.0640 & + & 299 & 292 \\
3 & $0.5-40-303$ & 55 & 0.0926 & - & 51.106 \\
4 & $1.1-40-303$ & 135 & 0.0788 & - & 294 \\
5 & $1.7-40-303$ & 220 & 0.0596 & + & 297 \\
6 & $0.5-30-303$ & 50 & 0.0655 & $\longrightarrow+$ & 293 \\
7 & $0.5-20-303$ & 50 & 0.0616 & -12.07 & 41.687 \\
\hline
\end{tabular}

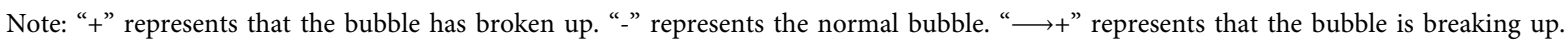

Void content generally has a negative relationship with mechanical properties, especially the mechanical properties dominated by interlayer properties. When the void content is between $1.7 \%$ and $2.3 \%$, the ILSS decreases fastest. Void content also has an adverse effect on FS. When the void content is more than $3 \%$, the FS is only about $75 \%$ of that without voids. This explains the trend of the curve in Figure 9. These trends are closely related to the different void content caused by bubble motion. Thus, in most of the curves, the mechanical properties and bubble characteristic parameters show inverse relationships compared with void content. For example, FS and ILSS are positively related to the maximum cross-sectional area of the bubble, while the void content is the opposite. A similar situation presents in the bubble displacement and maximum deformation of the fiber. The curves appear to increase first and then decrease. However, the relationship between temperature and mechanical properties is not obvious, which is in accordance with that of void content. It follows that the multiphase flow coupled simulations, especially the bubble cross-sectional area, can assist in controlling void defects and providing an effective way to improve the efficiency of the AFP process optimization. 


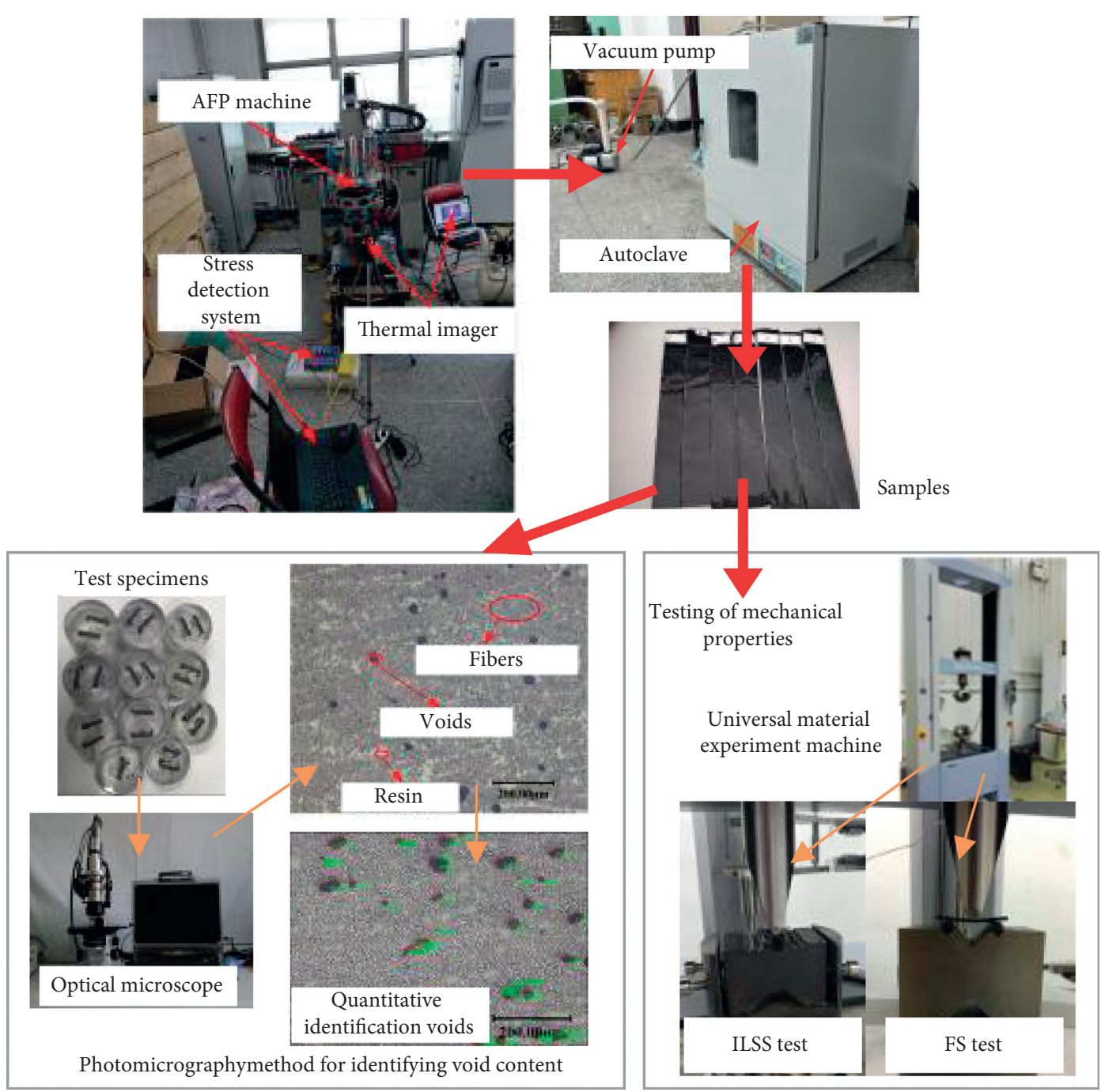

FIgURE 7: Experimental setup.

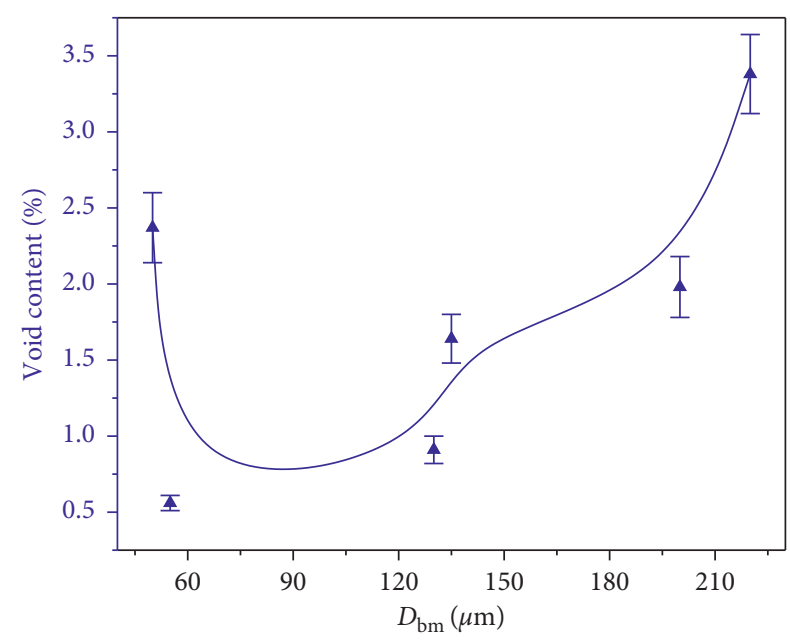

-₫- Void content

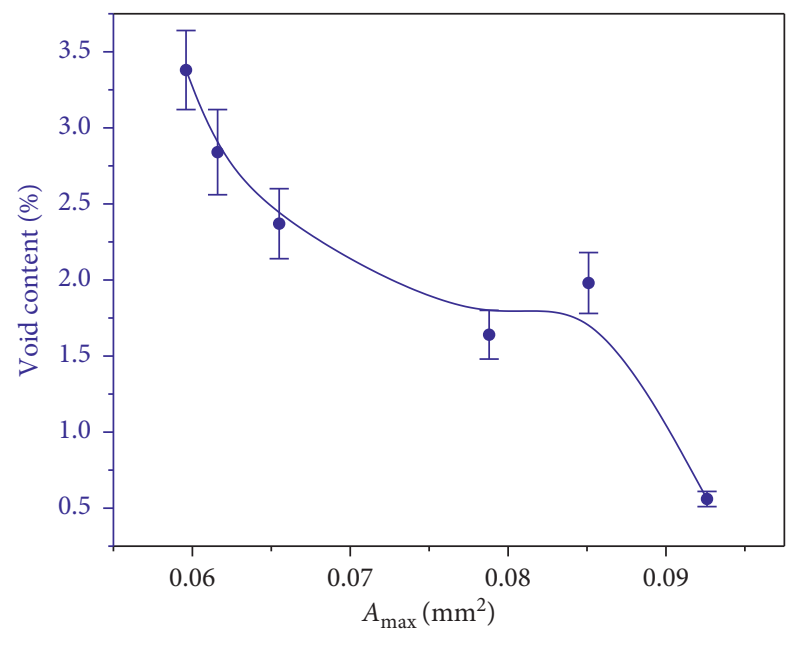

$\multimap$ Void content

(a)

Figure 8: Continued. 


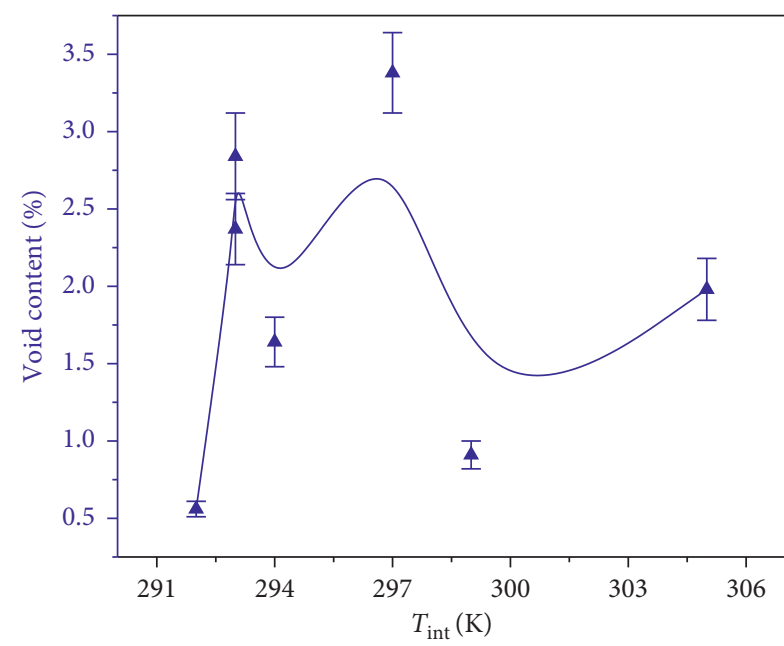

- - Void content

(c)

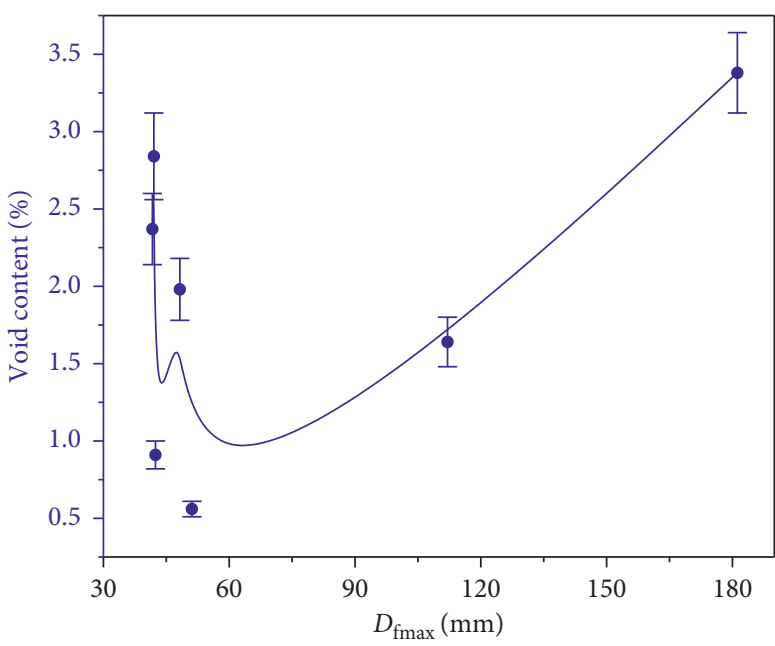

Void content

(d)

FIGURE 8: Relationship between void content and bubble characteristic parameters. (a) Bubble displacement $\left(D_{\text {bm }}\right)$. (b) Maximum crosssectional area of the bubble $\left(A_{\max }\right)$. (c) Void content and internal lowest temperature of the bubble $\left(T_{\text {int }}\right)$. (d) Maximum deformation of the fiber $\left(D_{\text {fmax }}\right)$.

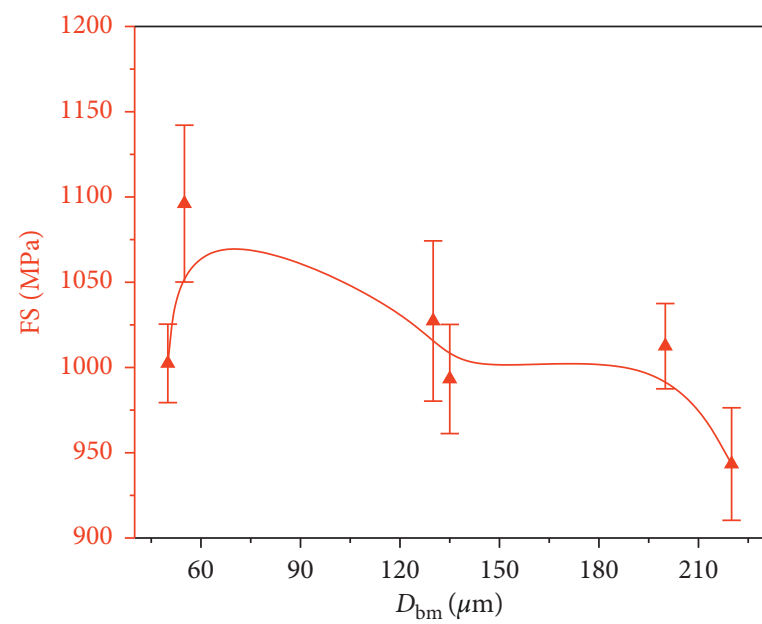

$\leftarrow$ Flexural strength

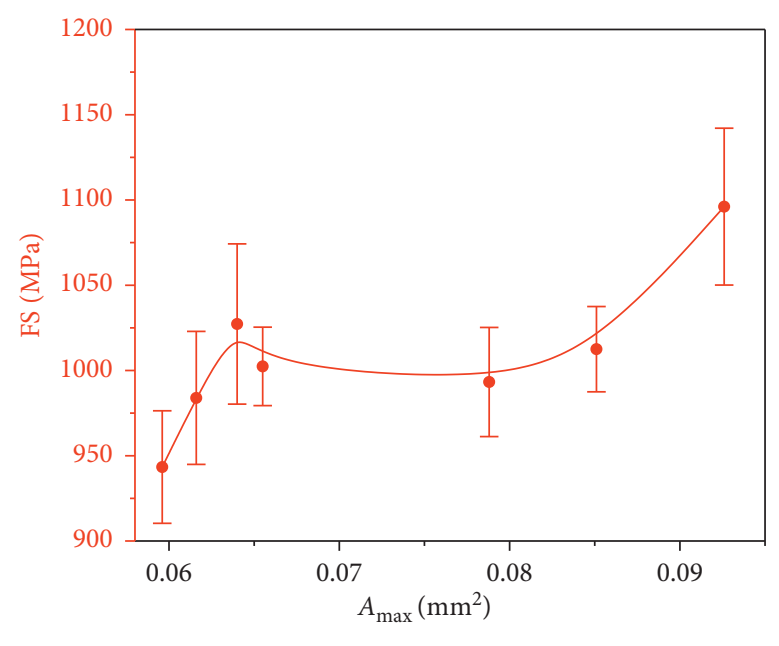

$\rightarrow$ Flexural strength

(a)

(b)

FIgURE 9: Continued. 


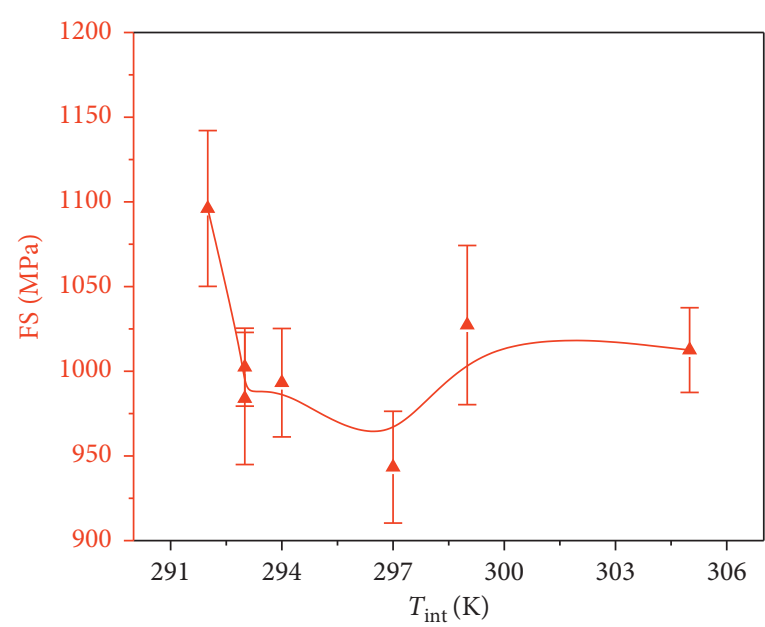

$\_$Flexural strength

(c)

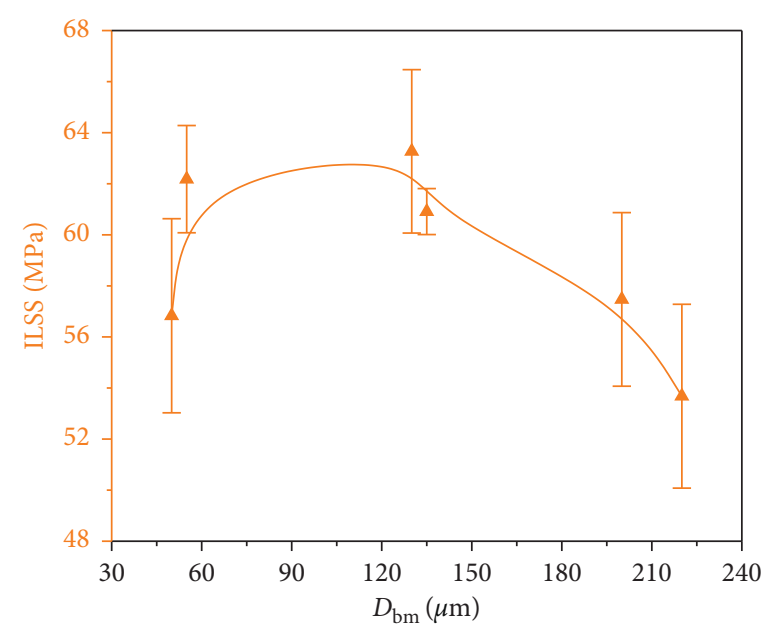

$\_$Interlaminar shear strength

(e)

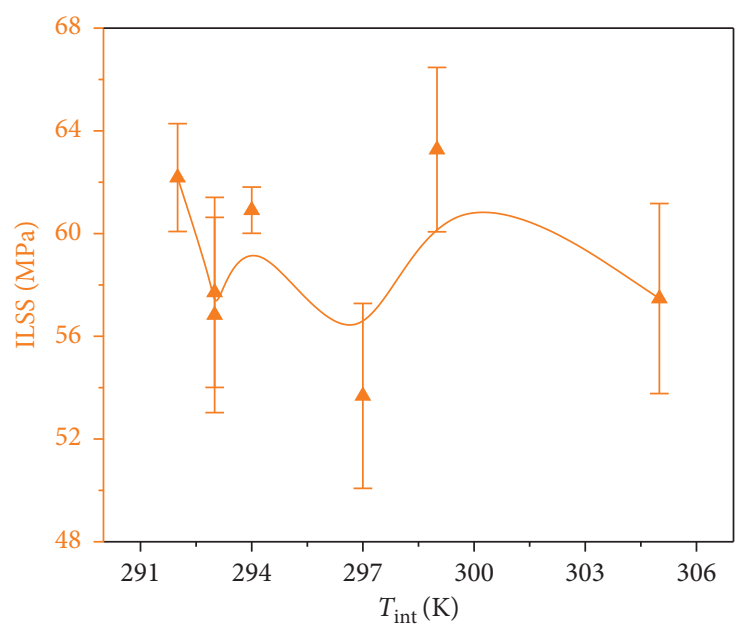

$\rightarrow$ Interlaminar shear strength

(g)

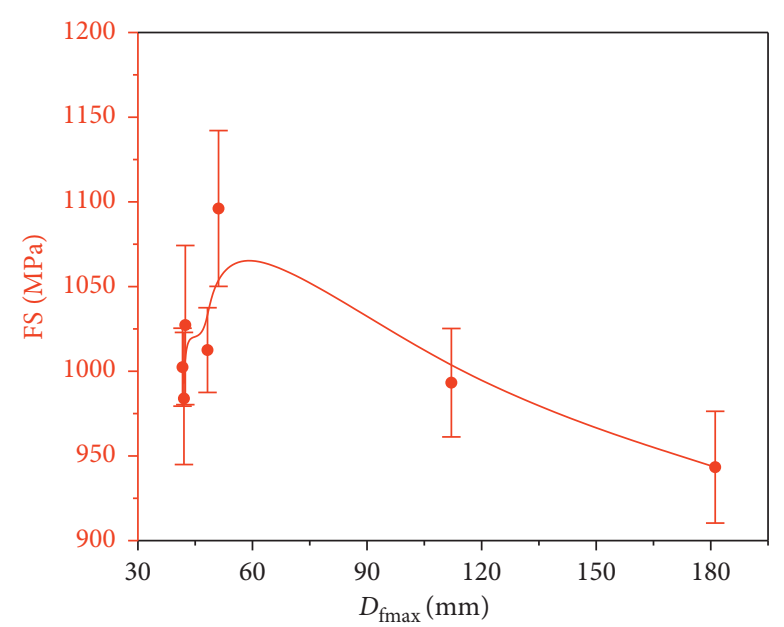

- Flexural strength

(d)

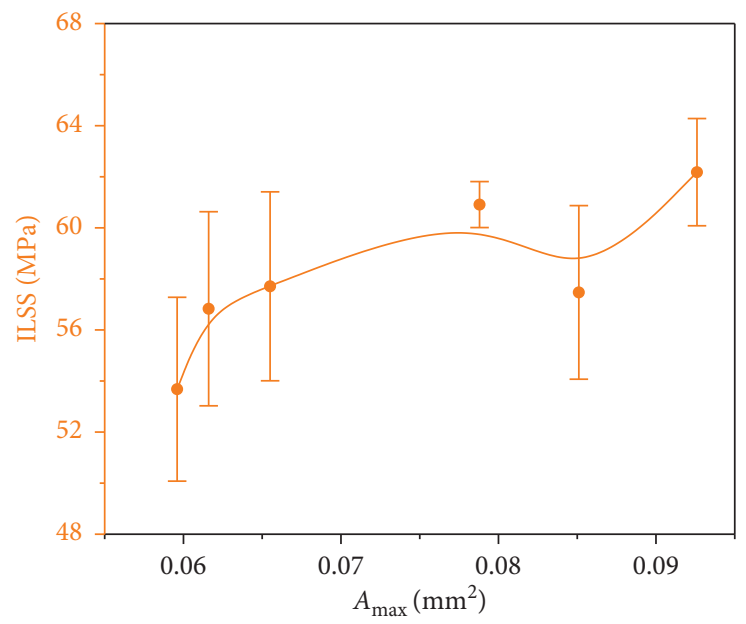

- - Interlaminar shear strength

(f)

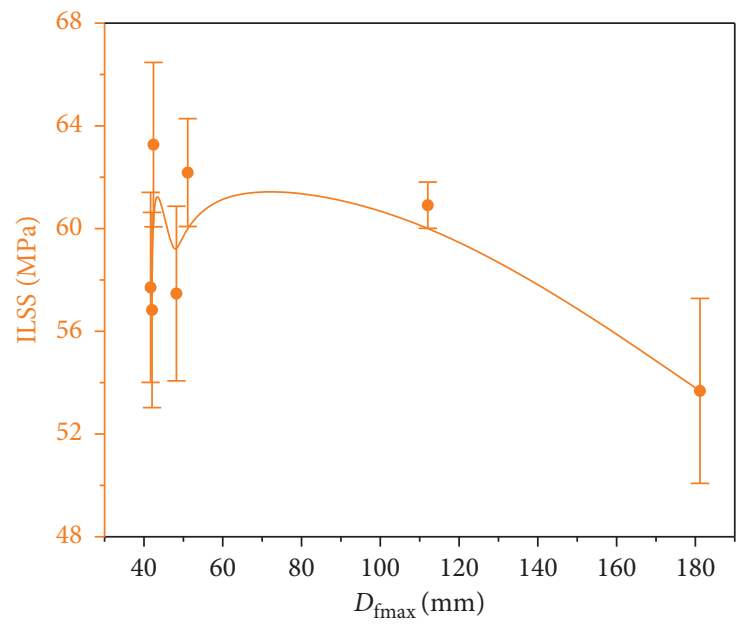

$\rightarrow$ Interlaminar shear strength

(h)

FIGURE 9: Relationship between bubble characteristic parameters and mechanical properties: (a) FS and bubble displacement. (b) FS and maximum cross-sectional area of the bubble. (c) FS and internal lowest temperature of the bubble. (d) FS and maximum deformation of the fiber. (e) ILSS and bubble displacement. (f) ILSS and maximum cross-sectional area of the bubble. (g) ILSS and internal lowest temperature of the bubble. (h) ILSS and maximum deformation of the fiber. 


\section{Conclusions}

Based on the presented analysis, the following conclusions can be drawn:

(1) The bubble displacement increases with the increase of the laying pressure and preheating temperature. Usually, the cross-sectional area of the bubble reduces with the increase of the laying pressure. Interestingly, the laying speed is opposite to that, which has a positive correlation with the cross-sectional area of the bubble.

(2) Bubbles are easy to break up at higher laying speed and preheating temperature or longer bubble displacement (more than $200 \mu \mathrm{m}$ ). The laying pressure has a positive effect on the internal lowest temperature of the bubble as well as the maximum deformation of the fiber.

(3) Void content decreases first and then increases as the bubble displacement or maximum deformation of fibers increases. This can be explained by the expulsion and convergence functions of the bubbles during the AFP process. Additionally, the bubble cross-sectional area and void content present a negative correlation.

(4) The mechanical properties of FS and ILSS are positively related to the maximum cross-sectional area of the bubble. FS and ILSS increase first and then decrease as bubble displacement and maximum deformation of the fiber increase, which are opposite to that of the void content. Moreover, there is no obvious correlation between FS, ILSS, and the internal temperature of the bubble.

The understanding of the relationship between the processing parameters and the bubble characteristics can help to establish a foundation for process optimization and void control during the AFP process. The results presented in this paper can assist in developing a theoretical framework or a mathematical model relating AFP processing parameters to the low-defect of the manufactured FRPs in the future.

\section{Data Availability}

The data used to support the findings of this study are included within the article.

\section{Conflicts of Interest}

The authors declare that there are no conflicts of interest regarding the publication of this paper.

\section{Acknowledgments}

The authors are pleased to acknowledge the financial support by the National Natural Science Foundation of China (no. 51375126).

\section{References}

[1] Z. Jia, T. Li, F.-p. Chiang, and L. Wang, "Experimental investigation of the temperature effect on the mechanics of carbon fiber reinforced polymer composites," Composites Science and Technology, vol. 154, pp. 53-63, 2018.

[2] K. Friedrich and A. A. Almajid, "Manufacturing aspects of advanced polymer composites for automotive applications," Applied Composite Materials, vol. 20, no. 2, pp. 107-128, 2013.

[3] Z. Y. Han, S. Z. Sun, Z. X. Shao, and H. Y. Fu, "Multiscale collaborative optimization of processing parameters for carbon fiber/epoxy laminates fabricated by high-speed automated fiber placement," Advances in Materials Science and Engineering, vol. 2016, Article ID 5480352, 2016.

[4] P. Ribeiro, H. Akhavan, A. Teter, and J. Warminski, "A review on the mechanical behaviour of curvilinear fibre composite laminated panels," Journal of Composite Materials, vol. 48, no. 22, pp. 2761-2777, 2014.

[5] N. M. Chowdhury, J. Wang, W. K. Chiu, and P. Chang, "Static and fatigue testing bolted, bonded and hybrid step lap joints of thick carbon fibre/epoxy laminates used on aircraft structures," Composite Structures, vol. 142, pp. 96-106, 2016.

[6] Z. P. Wang, L. Ye, and Y. K. Liu, "Electro-thermal damage of carbon fiber/epoxy composite laminate," Journal of Reinforced Plastics and Composites, vol. 37, no. 3, pp. 166-180, 2018.

[7] Q. Dong, G. S. Wan, Y. Z. Xu et al., "Lightning damage of carbon fiber/epoxy laminates with interlayers modified by nickel-coated multi-walled carbon nanotubes," Applied Composite Materials, vol. 24, no. 6, pp. 1339-1351, 2017.

[8] C. S. R. Souza, G. M. Candido, W. Alves, J. M. F. Marlet, and M. C. Rezende, "Morphological and mechanical analyses of laminates manufactured from randomly positioned carbon fibre/epoxy resin prepreg scraps," Materials Research Express, vol. 4, no. 10, Article ID 105601, 2017.

[9] S. Z. Sun, Z. Y. Han, H. Y. Fu, H. Y. Jin, J. S. Dhupia, and Y. Wang, "Defect characteristics and online detection techniques during manufacturing of FRPs using automated fiber placement: a review," Polymers, vol. 12, no. 6, p. 1337, 2020.

[10] S. Z. Sun, Z. Y. Han, J. H. Zhang, H. Y. Jin, and Y. Wang, "Multiscale collaborative process optimization method for automated fiber placement," Composite Structures, vol. 259, Article ID 113215, 2021.

[11] S. Z. Sun, Z. Y. Han, J. S. Dhupia, and H. Y. Jin, "Multi-scale Analysis of Interface Characteristics for CFRPs Made by Automated Fiber Placement," Mechanics of Advanced Materials and Structures, 2020.

[12] B. Milenski and V. Benson, "Recent advances in automated fiber placement," SAMPE Journal, vol. 50, no. 2, pp. 7-14, 2014.

[13] P. Hormann, D. Stelzl, R. Lichtinger, S. V. Nieuwenhoveb, G. Mazón Carroa, and K. Drechsler, "On the numerical prediction of radiative heat transfer for thermoset automated fiber placement," Composites Part A-Applied Science and Manufacturing, vol. 67, pp. 282-288, 2014.

[14] C. Baley, A. Kervoelen, M. Lan et al., "Flax/PP manufacture by automated fibre placement (AFP)," Materials \& Design, vol. 94, pp. 207-213, 2016.

[15] J. Frketic, T. Dickens, and S. Ramakrishnan, "Automated manufacturing and processing of fiber-reinforced polymer (FRP) composites: an additive review of contemporary and modern techniques for advanced materials manufacturing," Additive Manufacturing, vol. 14, pp. 69-86, 2017.

[16] Y. K. Hamidi, L. Aktas, and M. C. Altan, "Effect of nanoclay content on void morphology in resin transfer molded 
composites," Journal of Thermoplastic Composite Materials, vol. 21, no. 2, pp. 141-163, 2008.

[17] D. E. W. Stone and B. Clarke, "Ultrasonic-attenuation as a measure of void content in carbon-fiber reinforced-plastics," Non-Destructive Testing, vol. 8, no. 3, pp. 137-145, 1975.

[18] F. LeBel, E. Ruiz, and F. Trochu, "Void content analysis and processing issues to minimize defects in liquid composite molding," Polymer Composites, vol. 40, no. 1, pp. 109-120, 2019.

[19] S. Ranganathan, S. G. Advani, and M. A. Lamontia, "A nonisothermal process model for consolidation and void reduction during in-situ tow placement of thermoplastic composites," Journal of Composite Materials, vol. 29, no. 8, pp. 1040-1062, 1995.

[20] R. Pitchumani, S. Ranganathan, R. C. Don, J. W. Gillespie, and M. A. Lamontia, "Analysis of transport phenomena governing interfacial bonding and void dynamics during thermoplastic tow-placement," International Journal of Heat and Mass Transfer, vol. 39, no. 9, pp. 1883-1897, 1996.

[21] J. Tierney and J. W. Gillespie, "Modeling of heat transfer and void dynamics for the thermoplastic composite tow-placement process," Journal of Composite Materials, vol. 37, no. 19, pp. 1745-1768, 2003.

[22] P. Simacek, S. G. Advani, M. Gruber, and B. Jensen, “A nonlocal void filling model to describe its dynamics during processing thermoplastic composites," Composites Part A-Applied Science and Manufacturing, vol. 46, pp. 154-165, 2013.

[23] M. A. Khan, P. Mitschang, and R. Schledjewski, "Tracing the void content development and identification of its effecting parameters during in situ consolidation of thermoplastic tape material," Polymers and Polymer Composites, vol. 18, no. 1, pp. 1-15, 2010.

[24] D. Saenz-Castillo, M. I. Martin, S. Calvo, F. Rodriguez-Lencea, and A. Güemes, "Effect of processing parameters and void content on mechanical properties and NDI of thermoplastic composites," Composites Part A-Applied Science and Manufacturing, vol. 121, pp. 308-320, 2019.

[25] Z. Y. Han, S. Z. Sun, W. Q. Li, Y. X. Zhao, and Z. X. Shao, "Experimental study of the effect of internal defects on stress waves during automated fiber placement," Polymers, vol. 10, no. 4 , p. 413, 2018.

[26] C. Chan, Y. T. Zhang, Y. Z. Gu et al., "Study on the effects of processing conditions on void defect in carbon fiber/epoxy composites," Fiber Reinforced Plastics/Composites, vol. 5, pp. 51-55, 2014. 